\title{
Reducing Administrative Burdens as Part of the »Better Regulation« Programme - the Case of Slovenia
}

\author{
GREGOR ViRANT \& POLONCA KOVAČ
}

\begin{abstract}
The reduction of administrative burdens is an essential component of the Better Regulation programme in almost all EU Member States. The first part of the paper presents the BR programme as an attempt to modernise public administration, and it tries to define what good regulation means in accordance with various substantive and formal standards. It also describes the principles and standards of good regulation, together with the tools to achieve it. The following is a general and Slovenia-specific presentation of the removal of administrative burdens and barriers in terms of procedure simplification and deregulation (with particular emphasis on differences between process optimisation and deregulation), highlighting innovative solutions. The results, impacts, and shortcomings presented here are critically evaluated as a basis for further research.
\end{abstract}

KEYWORDS: - better regulation - reduction of administrative burdens/barriers $\bullet$ EU $\bullet$ Slovenia $・$ regulation quality $\bullet$ principles $\bullet$ standards $\bullet$ tools

CorResPondence AdDress: Gregor Virant, Ph. D., University of Ljubljana, Faculty of Administration, Gosarjeva ulica 5, 1000 Ljubljana, Slovenia, email: gregor.virant@fu.uni-lj.si. Polonca Kovač, Ph.D., Faculty of Administration, University of Ljubljana, Gosarjeva ulica 5, 1000 Ljubljana, Slovenia, email: polona.kovac@fu.unilj.si. 
With its systemic approach, the concept of better regulation (BR) has been a constant feature in the political and administrative setting of Europe and OECD member countries for almost two decades. One of its components is the removal of administrative barriers, which, together with other approaches, mainly contributes to the objectives of better competitiveness of states and national economies, and greater transparency and democracy of decision-making in public administration.

The ideas about improving the quality of regulations first appeared on the agenda of the European Union (EU) and its Member States in the 1990s when the Edinburgh Summit (1992) under the British Presidency expressed concern about the quality and quantity of regulations produced in Brussels. Yet, despite such findings, no country, with the exception of the UK, was able to establish a coherent policy in the 1990s. This was the policy with clearly set objectives and visible results (Radaelli, 2007: 35, 114). At the EU level, an important milestone was the Mandelkern Report (2001) drawn up by a group of experts within the context of the implementation of the Lisbon Strategy provisions regarding the improvement of the regulatory environment for businesses pursuant to the principles of necessity, proportionality, subsidiarity, transparency, accountability, accessibility, and simplicity based on the findings of the European Commission's (EC) analysis (Internal Market Scoreboard). According to the Mandelkern Report, for businesses alone, the burden of (unnecessary) regulation falls within the range of $4-6 \%$ of GDP of which $15 \%$ or more, i.e., at least EUR 40 billion, could be avoided (Radaelli and DeFrancesco, 2007, p. 35, 114). In the same year, the White Paper on Good Governance (COM (2001)428) devoted particular attention to the quality of regulation, resulting in some tangible proposals, such as the proposal to adopt minimum standards on public consultation, and the commitment to prepare an action plan for »better regulation«. In 2002, the Commission adopted minimum standards on public consultation and began to systematically carry out Regulatory Impact Assessment (RIA). Later in 2006, a special Impact Assessment Committee was set up for such a purpose, comprising high officials from the Directorates most closely associated with the three pillars of RIA, i.e., environment, social affairs, and economy.

In the EU and certain individual countries, the emphasis of the »better regulation" programme was initially mainly placed on regulation impact assessment and on consultation with experts and other interested public. In other countries and also in the EU later on, particularly during the time of the first Barroso Commission, increased emphasis was placed on reducing administrative burdens (Meuwese in Kovač, 2009: 97). In 2004, the Competitiveness Council called upon the EC and the Member States to evaluate the cumulative impact of the existing legislation on the competitiveness of industry and specific industrial sectors, and to develop a method for measuring administrative burdens (Council, 2004). In March 2007, the 
EU Council adopted the decision to reduce administrative burdens arising from EU law by $25 \%$ by 2012 . At the same time, it invited the EU Member States to set »equally ambitious goals« at the national level, although analytical findings proved that most countries, for example the Netherlands and Denmark, had engaged in BR and removal of administrative barriers even a few years prior to the Commission's invitation. Thus, it may be concluded that nowadays the BR policies are more or less integrally implemented within national and supranational structures where administrative burden reduction (initially oriented toward economic competitiveness) now mainly pursues the principles of democratic cooperation with the public (e.g., the Netherlands, the UK, and the European Union), or vice versa (e.g., USA, Scandinavia). However, the ideal scenario for a consistent BR policy comprises simultaneous and balanced development of RIA, public consultation, legislative drafting rules (nomotechnics), and removal of administrative barriers.

The first part of this paper aims at putting forth some effort for BR in the context of public administration modernisation processes, and at providing the definition of »good « or »better« regulation. Readers will see that regulation quality does not depend on the selection of political alternatives, but rather on politically neutral, substantive, procedural, and methodological standards. Individual governments pay increasing attention to various standards; emphasis varies from country to country and even from one period to another in the same country (Kovač, 2009: 18-21; Kirkpatrick \& Parker, 2007: 11-13). The selection of standards should not be understood as numerus clausus; the possibility to upgrade them should always be available.

The second part focuses on one of the key elements of good regulation, i.e., the reduction of administrative burdens and barriers. It deals with the definition of administrative burdens and barriers (whereby the distinction between the two is important). Particular emphasis is put on the boundary between simplification of administrative procedures resulting from procedure rationalisation / optimisation without decreasing the role of authority, with no risk for public interest, and from simplifications brought about by deregulation that imply a shift in the relation between the public and private spheres. These are the two processes with different political connotations that may have similar practical effects. This paper aims at putting the processes of removing administrative barriers into the context of BR.

The third part presents the case of Slovenia. The Slovenian Government started the BR process with removal of administrative barriers, or with what is known as the "anti-bureaucratic programme « launched in 2000. This was also the area that received the most attention in the following years, and which produced visible and measurable results that were recognised even by associations of small and medium-sized enterprises. The Slovenian case represents certain particular features. Thus, the 2007 SIGMA report acknowledged Slovenia's particular achievements in the area, considering evident progress. 


\section{The Term »Better Regulation« and the Legal Nature of »Meta- Regulation «}

The purpose of setting criteria and standards, and of using the BR tools is to optimise policy so that the benefits to society from the regulatory action are maximised and costs are minimised (Deighton-Smith in OECD, 1997: 211). The idea of improving regulation emerged as a result of several convergence processes in public administration. At the EU level, a contribution to the development of such an idea was made by the Lisbon Strategy that considers the regulatory environment important for the achievement of objectives under all three Strategy pillars: economic, social, and environmental. The idea of the BR is also associated with the development of new public management (NPM) and with the related introduction of total quality management (TQM). Considering that regulations (laws, formal and informal orders, and subordinate rules issued by all the levels of government and public authority holders) are some of the most important "products" of public administration, and that the process of drafting and adopting regulation is one of the main business processes in public administration, it is quite logical that the management and improvement of such a process have become an essential component of the TQM system. The government, wishing to introduce quality into the work of its ministries and agencies, or even aiming at business excellence of such organisations, must develop a quality regulation policy that follows the quality management principles. Although the current regulatory policy development does not take place within formal frameworks of quality management models, it nevertheless represents an important element of quality management. It can well be said that the changes in such an area comply with the quality management principles, and that without observing such principles, no change will ever be effective.

The term "good regulation « can be misleading because it implies individual or group satisfaction with the content of a regulation. Individual citizens have differing views on any regulation - depending on their philosophy of life, and on the circumstances in which they live. Tax reform will be more acceptable to those who will pay less tax than to those whose tax burden will increase. Yet, there are certain objective professional criteria to measure the quality of regulation. Such criteria are politically neutral. In such a sense, the quality of regulation does not depend on the selection of one or another political alternative. It is about the process and approach quality, tools, and methods of drafting and adopting regulations, and partially also about certain politically indisputable substantive standards (e.g., the necessity of regulation, pureness in terms of administrative barriers). Assessing the quality of regulation should not be biased in terms of prioritising more liberal, or more social, or interventionist approaches (OECD, 1997: 193; Radaelli \& De Francesco, 2007: 38).

The rules regulating regulation are often referred to as meta-regulation (Morgan, 2003: 57; Meuwese, 2008: 14). Regulation is a mechanism to regulate social 
relations, while meta-regulation (regulation of regulation) is a mechanism to ensure regulatory compliance with the principles and standards for quality. Regulation has an outward effect. Its observance and implementation are guaranteed by the state with its monopoly over the means of physical constraint (Kušej, Pavčnik \& Perenič, 1996: 80). On the contrary, meta-regulation has an inward effect, and it is binding only on the government, on public administration bodies, and their staff. Given its internal nature, meta-regulation is a series of standards whereby the government as organisation regulates its internal processes, which brings us back to the TQM where the management of processes (their identification, standardisation, and optimisation) is a key success factor of the organisation. Regulation quality standards are associated with the regulation quality improvement policy tools. Speaking of the BR tools, Radaelli and DeFrancesco (2007: 29) mention, inter alia, RIA, consultation, simplification, and regulation accessibility.

As regards the legal nature of meta-regulation, it can be said that internal government rules - in particular the rules of procedure, recommendations, and guidelines - prevail. Meta-regulation has a legislative effect only in some areas, mainly in environmental protection and spatial planning where impact assessment and public consultation are normally provided by law (the latter also owing to the Aarhus Convention requirements). Generally speaking, however, the rules governing regulations are legislative issues only in few countries (the US and Hungarian Administrative Procedure Act which, in addition to administrative decision-making procedures, also regulates the procedures for adopting abstract and general legal acts of public administration in specific cases). When regulation rules are laid down in internal rules, the observance of regulation quality standards is a matter of the internal discipline of the government and state administration, and consequently, even the matter of the development of political and administrative culture (cf. Deighton-Smith in OECD, 1997: 211-218). There are some arguments against setting the regulation quality standards at the legislative level, mainly due to the argument that quality regulation culture cannot be imposed, but should be gradually developed by using soft methods such as competency identification needed for policy maker jobs, an adequate employment policy for such positions, policy maker network building, and building adequate training modules. We believe that the enactment of quality regulation standards and drafting an appropriate constitutional provision within the framework of the right to good public administration (the constitutional provision should set a standard of public participation and decision-making based on facts and evidence) would contribute to a more rapid development of the BR processes and to faster changes in the "philosophy" of governments and policy makers in all countries, particularly in those under continental law. 


\section{Quality Regulation Principles and Standards, and Tools for Their} Achievement

Quality is defined by principles (Radaelli \& De Francesco, 2007: 32). International organisations and national governments have set a series of principles of good regulation. The Mandelkern Report (2001: 9) describes seven core principles: necessity, proportionality, subsidiarity, transparency, accountability, accessibility, and simplicity. A similar approach is used in the UK, with additional emphasis on the necessary consistency of regulations. For comparison purposes the Slovenian Resolution on Legislative Regulation $\left(2009^{1}\right)$ speaks of the principle of the necessary legal regulation imposing on the Legislature (the regulating authority) the necessity of producing an in-depth analysis of the policy (which is initiated or amended and supplemented) giving rise to the questions that need to be regulated, causes of problems, precise objectives, and methods of regulation), self-restraint (requiring from the legislator to make a responsible decision when regulating social relations by provisions, thus interfering with the social relations, human rights, and freedoms only to the extent strictly necessary to attain the objectives pursued, i.e., the legitimacy of the objective, justification of the interference), proportionality (minimum interference to be determined by the RIA), accountability (assuming political and professional accountability for decision-making), accessibility, simplification, and transparency (comprehensible regulation, the possibility of using modern tools, no unnecessary burdens, transparency of regulations with reasonable structure, correct and uniform terminology, codification of individual areas, preparation of consolidated texts, etc.).

Table 1: Principles of regulation in the EU and Slovenia (pursuant to the parliamentary Resolution)

\begin{tabular}{|l|l|l|l|}
\hline & $\begin{array}{l}\text { The quality regulation } \\
\text { principle according to } \\
\text { Mandelkern (2001); } \\
\text { for the EU }\end{array}$ & $\begin{array}{l}\text { The principle of } \\
\text { good regulation in } \\
\text { the } \mathrm{UK}^{2}\end{array}$ & $\begin{array}{l}\text { The principle of regulation } \\
\text { according to Resolution on } \\
\text { Legislative Regulation in } \\
\text { Slovenia (2009) }\end{array}$ \\
\hline 1 & Necessity & Targeting & Necessity of legal regulation \\
\hline & & & Self-restraint \\
\hline 2 & Proportionality & Proportionality & Proportionality \\
\hline 3 & Subsidiarity & & Accountability \\
\hline 4 & Transparency & Transparency & Transparency \\
\hline 5 & Accountability & Accountability & \\
\hline & & Consistency & Accessibility \\
\hline 6 & Accessibility & & Simplification \\
\hline 7 & Simplicity & & $\begin{array}{l}\text { Extra on cooperation with the } \\
\text { public: timeliness, openness, } \\
\text { availability, responsiveness, } \\
\text { transparency, traceability }\end{array}$ \\
\hline & & & \multicolumn{2}{|l}{}
\end{tabular}


The comparison shows that the list of principles is practically the same. The only difference is that instead of using the principle of subsidiarity (which is a term specific for the EU being a supranational organisation, although it can be used at the level of Member States in the relation between the central and local government), the term self-restraint is used. It largely overlaps with the principle of the necessity of legal regulation. Likewise, the Resolution pursues the integrity of regulatory management with explicit inclusion of public participation, RIA, interdepartmental cooperation, and reduction of administrative burdens into legislative regulation. As mentioned above, the efforts for the BR are concordant with the introduction of the TQM principles into public administration. Therefore, the list of principles from the Mandelkern Report could be supplemented with the following quality management principles (cf. ISO 9001):

- $\quad$ the process management principle: the processes of drafting and adopting regulations must be managed and carefully standardised (with due consideration of the necessary flexibility),

- decisions regarding regulation must be based on facts and evidence,

- a close link must be established with the »users« (in particular the addressees of regulations, as well as the implementers),

- the principle of continuous improvement: on the one hand, this principle signifies that the regulatory policy must contain the principle of continuous improvement (such a policy must be regularly examined and, if necessary, amended), but on the other hand, it signifies that constant evaluation and improvement of individual regulations is an important standard of quality regulation,

- the management principle: the top management in public administration (i.e., prime minister, ministers, and senior management in ministries) must be informed of the importance of such processes, and it must be sincerely committed to these goals.

The above principles take a concrete form in the quality regulation standards enshrined in the regulatory policies of the EU and its Member States. The process of adopting decisions and policies is shown here with what is known as a regulatory cycle that comprises three main stages: (1) policy development (planning), (2) implementation, and (3) evaluation or revision. All the three stages are equally important because each of them serves as a basis for the following stage that creates a closed loop (see Figure 1). 
Figure 1: Regulatory circle (Manual for the Implementation of the Resolution on Legislative Regulation, 2010).

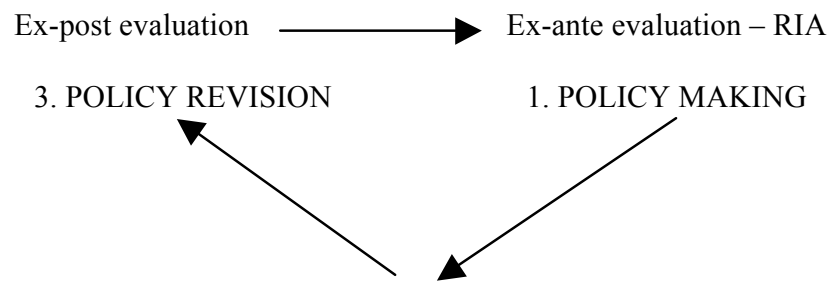

2. POLICY IMPLEMENTATION

Interim evaluation

Let us try to analyse the notion of quality regulation by defining the standards and linking them with the tools for their achievement. The first element (i.e., the element of necessity) signifies that the government that wants to introduce a new policy must ascertain whether a new regulation should be adopted or the existing one should be amended (Mandelkern, 2001: 9). The element of necessity may be examined during the impact assessment, or it can be an independent process carried out in addition to the impact assessment. The proposer of the new regulation must ensure that the regulation is necessary, and thereby taking full responsibility for such a statement. Thus, the evidence of the necessity of the regulation needs to be provided together with the definition of the framework and objectives of the regulatory measure or public policy with integral identification of the problem that calls for government (authority) action, and the definition of the regulatory and other possible solutions (Kirkpatrick \& Parker, 2007: 4; OECD, 2008: 16). In order to adopt regulation only for the areas where it is necessary, and in order to ensure its quality implementation, legislative and similar procedures should be modernised by means of the institutionalisation of the cooperation with the public and addressees of the regulation (cf. Radaelli \& De Francesco, 2007: 188). In identifying the possible alternatives, Slovenia also looks for solutions and practices in other EU Member States. At least three possibilities need to be indicated (according to the Rules of Procedure of the National Assembly, this is an essential component of the materials for discussion in Parliament, yet it only applies to laws and not to implementing regulations, although the volume of the latter is constantly increasing). On the other hand, proportionality signifies that regulation must balance the limitations and obligations with the benefits and advantages. Proportionality, too, is normally evaluated by means of the RIA.

Decision-making based on facts is guaranteed by RIA. Here, the assumption is that better information leads to better regulation because decisions are optimised. An interesting paradox needs to be mentioned. In practice, it occurs when data (upon request of politicians) are gathered to prove the hypotheses that have already been formed in advance (policy-based »evidence«; cf. Bertelsmann, 
2010). Such a process (and the document resulting from it and available to both final decision makers and the public) evaluates the impacts of regulation on the economy, the environment, and social affairs. Impact assessment affects the quality of a regulation mainly because it gives decision makers a clear picture of the consequences of such a regulation in practice. This also makes the selection of political alternatives easier (it is therefore recommended that assessment be done for several alternative decisions). Impact assessment represents an empirical element of the formulation and adoption of regulations ${ }^{3}$. Decision makers who have comprehensive information about the impacts of the proposed solutions can assume full responsibility as they know better the decision they make. RIA as a tool enabling decision-making based on facts and evidence is directed toward optimising policy effects and giving priority to long-term positive impacts of the regulation over short-term impacts. However, the limited scope of such a tool needs to be taken into account because it is not a surrogate for a political assessment, but rather an aid for policy makers ${ }^{4}$. A comprehensive and correct impact assessment also enhances the possibility of criticism regarding the regulation (expressed by media, civil society, opposition, etc.), and it gives more power to the institutions of informal and formal political control. Moreover, it improves the conditions for public participation in the processes of drafting and adopting a regulation. In fact, the interested public have no human resources to carry out such assessments, while a professionally integrated, grounded, and convincing impact assessment indeed discourages criticism and disagreement resulting merely from fear or non-understanding. As described above, RIA significantly contributes to reducing the democratic deficit and has a positive effect on the legitimacy of regulation. RIA is particularly necessary in connection with the reduction of administrative burdens for certain subjects as addressees of the regulations.

Drafting and adopting a regulation must also involve the interested public. Public participation or public consultation has a multi-layer significance. It positively affects the quality of the regulation. The involvement of the expert public (experts from universities, research institutes, the economic sector, etc.) and of the public affected by the regulation (i.e., the interested public) allows the regulation maker to gain a better insight into the relevant information about the actual state of affairs. Public consultation also enables the regulation maker to early detect possible conflicts and disagreements, and to make a well-considered decision about whether or not the benefits of the disputed solution outweigh the negative consequences of the conflict. Moreover, the participation of the interested public means preserving the partnership between the government and administration on the one hand and the civil society on the other. Such a partnership and mutual respect have a further positive effect on the implementation of the regulation. The addressees would consider a regulation more legitimate if they had a possibility to participate in forming it - even if not all of their comments were taken into consideration. Public consultation has, of course, an important role regarding the democracy of public administration processes because it increases openness and 
transparency of the work of the government and public administration, thereby reducing the democratic deficit - the lack of a wider democratic debate during the adoption of political decisions. The more reserved and distant the decision-making institutions are from civic supervision, the more evident is the democratic deficit. It is therefore particularly present in the adoption of implementing regulations where debates and decision-making remain within the scope of the Executive. On the one hand, consultation is a tool that helps achieve other standards (facts-based decision-making, proportionality, etc.), but on the other hand, it is a standard per se, i.e., a procedural standard. The quality of decision thus depends on the quality of the relations between administration and the public, and on the ability of mutual communication (Schuppert, 2000: 740).

The public administration has two main functions: to prepare expert groundwork for the adoption of political decisions and to implement the adopted policies. Organisationally speaking, these two functions are more or less separated. Policymaking occurs in ministries, while the implementation of the adopted policies falls within the competence of more or less independent agencies. There has to be a regular flow of information between the makers and the implementers of regulation. In the drafting stage, the regulation must be »cleaned " of all administrative barriers - burdens that do not contribute to the objective of the regulation, or they are not proportional therewith. The addressees see such a regulation as rational, thus conferring on it greater legitimacy where its positive impact must be proven by the fact that the regulation actually brings more advantages than burdens or costs.

Another element of quality regulation is also coherence. The government's policy should not be merely a sum of ministerial policies, but it should be consistent, coherent and strategically conducted. The tool for ensuring coherence of regulation is horizontal inter-ministerial coordination. During inter-ministerial coordination, the regulation belonging to the scope of one ministry is highlighted from the viewpoint of other ministries. The regulation that is balanced from the viewpoint of diverse public interests and does not pursue public interest in merely a single area is given greater legitimacy. Modern BR textbooks seldom refer to the "stiff « elements of quality that are traditionally rooted in public administration such as consistency, nomotechnical quality, compliance with the legal system (with similar or superior regulations), and the linguistic and stylistic quality. A regulation with linguistic or nomotechnical shortcomings, and a regulation that is inconsistent with the constitution or EU directives cannot be considered as quality regulation. Furthermore, quality regulation is characterised by accessibility of regulations for the users. Accessibility is provided through adequate publication, mainly on the Internet. Regulations must be published in a clear form, i.e., as consolidated texts, so that the users are not forced to »combine« the basic text with its further amendments. Additionally, one has to take into account the impact of the interpretation of legislation in the process of its implementation on the legal standing of citizens and undertakings, in administrative and judicial praxis as well. 
Therefore, in addition to the regulation text and internal guidelines for implementing it, the main precedent decisions of administrative bodies and court judgements must be published in a transparent manner.

Within organisations, quality is based on Deming's »Plan-Do-Check-Act« cycle. Such logic is also useful in regulation. The regulation role is to plan socially useful solutions to be implemented by public administration bodies and courts. The responsibility of the regulation makers does not end with the regulation adopted by the minister, government, parliament or local council. Their responsibility also includes the actual functioning of the regulation in practice, and constant adjustment to changes. Practice may show certain deviations from the desired objectives, and the situation in the society can change so that regulation needs to be adjusted. Regulation makers must carefully monitor its implementation. They must gather any relevant information from the implementers, analyse it and translate it into relevant indicators. At the same time, they must regularly collect useful proposals from the »users«, i.e., citizens, undertakings, associations, etc. Based on collected information, indicators, and proposals, they must periodically evaluate the regulation and prepare the necessary amendments. The process of continuous improvement is one of the main quality postulates, and regulation should not be an exception thereto. Since regulation makers are not infallible, improvements are necessary despite impact assessments and other tools. Real life quite frequently shows unexpected hidden effects of regulations. Other reasons for the necessity of improvement are the changes in the social environment to which we respond with amendments of the regulation.

The quality of a regulation should not be judged by the number of amendments thereto adopted. It is erroneous to assume that the best regulation is the one that is subject to the fewest amendments over a certain period of time. It is quite possible that its "non-amendability « is the result of a stiff approach of regulation makers, and of absurd defence of poor solutions. We should not buy arguments such as: »My« law is really perfect; it has not been amended for ten years. In all areas, continuous improvement must become a constituent part of the regulatory process, and the public administration culture must accept the fact that quality can only be assured through continuous efforts. The following table shows quality regulation standards and the tools to achieve them. 
Table 2: A model of corresponding quality regulation standards and tools

\begin{tabular}{|l|l|}
\hline Standard & Tool \\
\hline Necessity & Regulatory impact assessment (RIA) \\
\hline Proportionality & RIA \\
\hline $\begin{array}{l}\text { Facts and evidence-based decision- } \\
\text { making }\end{array}$ & RIA \\
\hline Knowledge of public opinion & Consultation \\
\hline Knowledge of implementer's opinion & Consultation \\
\hline Absence of administrative barriers & RIA, reduction of administrative barriers \\
\hline Coherency & Inter-ministerial coordination \\
\hline $\begin{array}{l}\text { Technical« standards (legal correctness, } \\
\text { linguistic correctness, comprehensibility, } \\
\text { logic consistency) }\end{array}$ & Revision \\
\hline Accessibility & Publication \\
\hline Continual improvement & $\begin{array}{l}\text { Gathering feedback from implementers, } \\
\text { gathering citizens' proposals, evaluation }\end{array}$ \\
\hline
\end{tabular}

All the above and similar quality standards may be gathered under a single umbrella - Regulatory Management Systems (according to Bertelsmann, 2010). Considering quality management tools, BR can be understood as a procedure or document, or an analytical report, yet the »true« BR is far more than that, and being a set of approaches together with similar tools, it extends deeply into the pores of the democratic organisation of the state. Therefore, one should distinguish the procedure and the form on one, and the overall good governance as an objective of BR on the other hand; whereby the first should be subordinated to the second. The BR development is, for example, clearly seen through RIA development in both ways within the EU. The Commission develops RIA because it has set itself an ambitious goal to reduce regulatory administrative barriers by $25 \%$ by 2012 (Hardacre, 2008, 6). It started with RIA as early as 2001, and it adopted specific guidelines in 2005. Yet only in the last two years has RIA been considered a system, and account is also taken of non-regulatory measures.

The above standards are normally evaluated in some form of »external control«. Their achievement falls under the responsibility of the proposer, although governments also provide ex-post control (at least technical, if not substantive control). Control may be organised in a centralised (exercised by a single body, e.g., RIA Committee of the EC, Meuwese in Kovač, 2009: 98-101) or decentralised manner (individual regulatory standards are evaluated by different bodies ${ }^{5}$ ). Compliance with quality regulation standards results in the documents accompanying the draft decision, and standards are integrated into the regulation development process. "External standards « affect processes, and the only correct approach is to make to comply with the said standards and to integrate them into the relevant processes from the beginning of the regulation drafting (in some cases, from planning). Similarly to other public administration projects, the main part of improving the regulation quality is to change the organisational culture. 
This is also the most important challenge for professional and political supporters of this project.

\section{Better Regulation And the Reduction of Administrative Burdens / Barriers}

Administrative burdens or administrative costs are the costs that the public and private sectors incur because of regulation. On one hand, any new regulation brings costs for the public administration - namely the costs of preparation and implementation of the regulation. On the other hand, individuals and organisations of the private sector face costs when providing compliance with the regulation. Businesses incur direct costs (taxes and other public financial commitments to public authorities), regulatory compliance costs, capital costs (reduced value of investments resulting from amended regulation), and indirect costs or costs of reduced efficiency (reduced volume of innovative solutions because of time spent on regulatory compliance) (Frick \& Ernst, 2008).

Figure 2: $\quad$ Regulatory cost categories (Frick \& Ernst, 2008)

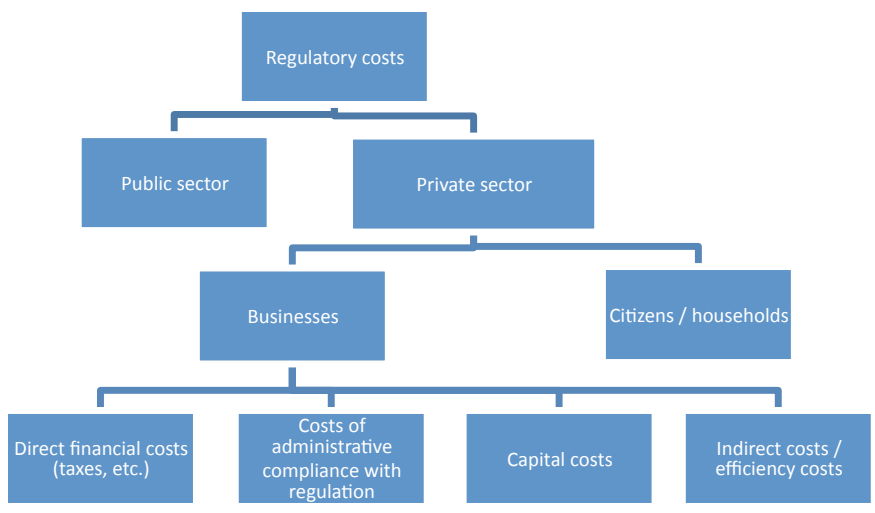

Regulatory compliance causes various costs. The regulation may require businesses to fulfil certain conditions for carrying out their activities (staff qualification, occupational safety equipment, etc.), meet specific internal (bookkeeping, drafting rules on occupational safety) or external administrative obligations (registration, acquiring a licence, providing data to public authorities).

Here, RIA and the reduction of administrative burdens overlap and complement each other with synergy effects. RIA is in fact a well-developed set of approaches aimed at eliminating or preventing the adoption of unnecessary regulations and other regulatory measures causing unnecessary costs or other undesired side effects. RIA is a method to analyse policies intended to support decision makers in designing, implementing, and monitoring improvements in regulatory systems in 
terms of good governance (Kirkpatrick \& Parker, 2007: 1-2). RIA is an internationally accepted analytical and communication tool that has been used in public administration throughout the world for the last two decades in order to remove unnecessary regulation and improve the quality and implementation of regulations. A special part of RIA is the ex-ante and/or ex-post evaluation of regulatory impact on the economy because there is an increasing awareness that administration should become a stimulating factor for the competitiveness of national economy. By strengthening the transparency of regulatory decisions and their rational justification (OECD, 2008: 14), RIA in fact strengthens the credibility of regulatory responses and increases public trust in regulatory institutions, the process, and public policy makers.

The methodology for measuring regulatory compliance costs (the Standard Cost Model, SCM), developed by the Dutch government (Frick \& Ernst, 2008: 66, cf. for Slovenia Klun and Slabe-Erker, 2009), is focused on the costs of administrative compliance with regulation, i.e., the costs that businesses face in adjusting their internal or external operations to regulatory requirements. By analogy, administrative costs can also be calculated for citizens or households. Any decrease in such costs for businesses is a relief, and it improves their position in the market, also compared with businesses in other countries. By simplification and reduction of administrative burdens, governments can set up a more competitive business environment.

Speaking of simplification and reduction of administrative burdens or costs, two types of measures are to be distinguished. On the one hand, there are measures aimed at rationalising administrative and other procedures, and removing unnecessary elements in such procedures without changing in any way the extent of state supervision or public interest protection. If, for example, regulation requires a company to send the same data on two different forms to two administrative bodies, it can be amended so that the company is required to send data only once. In addition, it is also allowed to send them by means of a web form that can be linked to the company information system so that reports are generated automatically. In such a case, the company will save some money while both administrative bodies will still receive the data needed for their work. This is the process optimisation that in no way alters the relations between individuals and businesses on the one side and the state on the other. The same public objectives are achieved in a simpler manner. These are organisational and managerial measures with no political components. It means removing unnecessary and irrational elements in procedures, and leading to rationalisation of processes. Rationalisation may, for example, be attained by applying the principles of »one stop shop«, »single sign on«, and »let the data circulate instead of the citizens $\ll$. The constant application of these three principles can indeed lower the costs of businesses and households ${ }^{6}$. 
Another form of simplification is the reduced extent of regulation in a specific area, e.g., elimination of the need to obtain a licence for a certain activity, or reduction of a number of conditions (or their complexity) that need to be met for individuals to enter an activity. This means more than a mere administrative simplification, process optimisation, or managerial and organisational measures. It involves deregulation, i.e., a substantive law element rather than a procedural modification of the extent of state supervision, or a change in the relation between the public and private spheres. Deregulation also includes a political component because the attitude towards such a process depends on the attitude towards the relation between the state and individuals.

In practice, citizens and businesses perceive both forms of simplification in the same manner. They reduce the costs of the measures necessary to comply with regulation. In order to separate the two types of simplification, we should speak of removing administrative barriers, and of deregulation, together known as reduction of administrative burdens. An administrative barrier is any irrational or unnecessary element in the relation between individuals or businesses on the one side and public administration on the other. These elements can be removed without detriment to the public interest or benefits provided by regulation. But on the other hand, deregulation is the process of amending regulation towards reducing the extent of state supervision and altering the relation between the public and private spheres. The removal of administrative barriers does not take place only at the level of regulation, but also at the level of its implementation. It falls under the responsibility of both regulation makers and implementers. The responsibility for a successful removal of administrative barriers is thus distributed among:

- $\quad$ regulation makers in state and local administrations, and policy makers who adopt the final decision regarding the adoption of regulation

- the political strategic centre for removal of administrative barriers; at the state level, this is a ministry or the office of the prime minister conducting and directing the entire process, and

- implementers who need to implement regulation with minimum costs and delays for citizens and businesses.

A part of responsibility is assumed by citizens and businesses that (through their appropriate demands and critical attitudes) can contribute to government responsiveness, and thereby providing useful proposals for reducing administrative burdens

Evaluation and improvement are also necessary for regulations adopted in a developed culture of regulatory management. It is even more important to evaluate previous regulation and to prepare improvements (Kovač, 2009: 11). Both approaches are important for the removal of administrative barriers. On the one hand, the preparation and adoption of regulations must ensure an exact overview, an estimation of administrative costs, and the »clean-up« of administrative 
barriers, while the other proposals should be gathered on a regular basis on how to remove administrative barriers in old regulations. Such proposals may be realised based on the "case-driven « system, i.e., by considering proposals while the regulation is still being discussed. Another possibility is to draw up a systematic action plan based on the proposals, binding on the persons responsible to initiate a procedure for the regulation amendment by a certain deadline. The purpose of it is to remove administrative barriers.

\section{The Removal of Administrative Barriers in Slovenia}

The activities to remove administrative barriers were launched in Slovenia prior to 2000. The first results were achieved during the 2000-2004 government term. As in the European Union, the removal of administrative barriers was furthered by implementing the Lisbon Strategy (Kovač, 2009: 47) in Slovenia. As early as 2000, the Office of the Prime Minister appointed a State Secretary to coordinate the inter-ministerial »anti-bureaucratic programme«. During that period, administrative procedures were significantly simplified. In the 2004-2008 term, the removal of administrative barriers became one of the priority policy objectives. The responsibility for the project was assumed by the newly established Ministry of Public Administration. It suggested the government to take a systematic approach to removing administrative barriers whose main characteristics were the following:

1. The process comprises a preventive approach and the »clean-up« of existing regulations. Such a preventive approach is based on the standard for removing administrative barriers, incorporated in the process of drafting and adopting decisions through RIA. According to Article 8 of the Government's Rules of Procedure (amended in 2006), the proposer of a regulation (minister) must provide the regulation impact assessment also in the area of removing administrative barriers. Should the regulation have any impact on the procedures or public administration interaction with users, the proposer must indicate the reasons why the procedure or some other administrative obligation are necessary and which public interest is going to be fulfilled. Moreover, the proposer must state evidence and explain why a public interest cannot be achieved in some other way that is client-friendly. In addition, it must be proven that the one-stop-shop principle (the principle that the client no longer has to fulfil administrative obligations concerning a particular life or business event at several locations) is respected. The proposer must specify the documentation that the client needs to submit for carrying out a procedure, thereby explaining a possible reduction of the extent of the documentation to be submitted, or giving the reasons why this is not possible. The procedure must be included in the e-government service portal by indicating the area and the business or life event to which the procedure refers. There must also be an indication of the data (to be retrieved from official records to carry out the procedure) and the data acquisition $\operatorname{method}^{7}$. 
Initially, the Slovenian ministries regarded the $\gg$ removal of administrative barriers « as unnecessary complication, but they gradually adopted such a standard to largely integrate it into the philosophy of their operation. The Ministry of Public Administration plays an important role. It acts as a supervisor that checks the accuracy of the impact assessment in the area of administrative barriers, and it draws attention to the barriers that are still left in the proposal. The political role of the Minister of Public Administration is to insist (in interactions with fellow ministers and at government sessions) on the comments presented by the service department responsible for the removal of administrative barriers, yet not taken into account by the proposer. Most comments are coordinated at the expert level, while some issues are finalised at the political level. Experience shows that the active role of the minister responsible for the removal of administrative barriers is very important, and likewise the support of the Prime Minister who also needs to devote sufficient attention to such an issue ${ }^{8}$. In 2007, a negative opinion was given to $40 \%$ of regulations; in 2008, when the expert service of the Ministry of Public Administration examined nearly 900 regulations (out of which there were 51 laws), a negative opinion was expressed on over $30 \%$ of regulations $-57 \%$ of them were laws, $31 \%$ government decrees, and $29 \%$ ministerial rules. In the first half of 2009, a negative opinion was given on slightly more than $17 \%$ of regulations.

Table 3: A statistical overview of the system for removal of administrative barriers in Slovenia (source: Ministry of Public Administration)

\begin{tabular}{|l|l|}
\hline Year & $\begin{array}{l}\text { Share of regulations rejected due to established administrative } \\
\text { barriers }\end{array}$ \\
\hline 2007 & approximately $40 \%$ \\
\hline 2008 & slightly over $30 \%$ \\
\hline 2009 & less than $20 \%$ \\
\hline
\end{tabular}

On the assumption that the ministry's approach has always been equally strict ${ }^{9}$, these data prove that the regulation makers' approach is changing, and that setting standards and introducing control actually lead to a change in »culture«. The reasons for rejecting the proposed regulations are: the burdens imposed by such regulations on business entities, and burdening the companies with administrative formalities that lead to reduced competitiveness. On the other hand, the potential of removing administrative burdens slowly decreases because it eventually turns into fine-tuning of the existing regulation. This is also evident from the data on estimated savings (SCM methodology) from 2006-2009. During that period, the amount of savings was 238.962 million euros (approx. 40 million per year). However, in 2010, only 5.467 million euros are expected to be saved.

The preventive action process incorporated into the RIA system largely prevents new administrative barriers from occurring. However, this alone is not sufficient to remove the existing barriers. For this purpose, the Ministry of Public 
Administration systematically gathers proposals from citizens, businesses, associations, and civil servants to simplify procedures (oao.predlogi@gov.si). The ministry analyses them together with other competent ministries. Based thereon and on the proposals from competent ministries, every autumn, it draws up an action plan for the next year to remove administrative barriers. The plan is adopted by the government, and it is binding on all ministries. Finally, the ministry draws up the programme implementation report. In such a manner, over 100 simplifications were implemented per year during the 2007-2009 period. Particularly worth mentioning was the abolition of the income tax declaration for citizens in 2008. Since then, the Tax Administration has been sending each taxpayer an informative income tax estimate. The taxpayer may check and object to it. In over $90 \%$ of all the cases, taxpayers have no further administrative obligation in relation to their income tax. If no objection is presented, the same document automatically becomes a decision and payment instrument. The tax authority has proved to be an efficient service provider, while the informative advance estimate (which is an executory instrument rather than a pre-compiled forecast with legal nature) makes the Slovenian regulation of income tax procedure one of the most advanced and efficient in the world (Klun and SlabeErker, 2009).

2. Contrary to the projects implemented at the level of EU institutions, and focused on the simplifications for businesses, the Slovenian project involves removing administrative barriers for both businesses and citizens, and considering the simplifications carried out until 2009, it might be even more efficient for the citizens. The removal of administrative barriers is a centrally run project (proposals are gathered at one spot, there is a single action plan for both categories of »users«, and preventive anti-bureaucratic check is carried out by the same service department). Some simplifications are useful to both citizens and businesses, e.g., a general rule of administrative procedures, whereby the competent bodies must retrieve data from official records themselves. The responsibilities for removing administrative barriers are distributed between the proposers of the regulation and the Ministry of Public Administration. The latter has a strategic responsibility for the area where the public consider the ministry responsible for "making bureaucracy simpler«. The Minister of Public Administration can focus on this issue and enforce standards for removing administrative barriers at the highest political level.

3. The project is also closely related with the e-government project that indeed corresponds to the frequently emphasised argument that process renovation is inseparably linked with computerisation, and that IT introduction cannot be successful without improving the processes. An excellent example thereof is the already mentioned the $\gg$ One-Stop-Shop « project: all the processes concerning the setting up a business, and the administrative obligations related thereto are integrated into a comprehensive information system with the organisation and computerisation of back office processes. 
Despite the above achievements and a clear vision of the targeted approaches, BR is not an integral system in Slovenia because the removal of administrative barriers obviously outpaces other pieces of the puzzle. What mainly lags behind is the implementation of the otherwise ambitious Resolution on Legislative Regulation adopted by Parliament in late 2009. An analysis of possible reasons shows that, similarly to other countries, Slovenia might lack the political will at the highest level, which, for the removal of administrative barriers, was obvious and even proven through the impact at the operational level mainly during the 2006-2008 period. The BR objectives cannot be achieved by removing administrative barriers alone. More so, the backlogs of other tools of quality regulation, e.g., inter-ministerial coordination or public consultation, even limit the efforts and results of removing administrative barriers.

\section{Conclusion}

The »Better Regulation« project that includes removal of administrative barriers plays an important role at the EU and national government levels. Quality regulation represents carefully defined principles and standards, and it has developed adequate tools to achieve them. The BR processes should also include the TQM principles because regulation is one of the basic "products" of governments and public administration. The list of quality regulation standards must be open. This paper highlights a few key standards that have not yet been fully enforced, e.g., cooperation of implementers and continuous improvement of regulation as a key principle of quality management. A separate question is how the principles and standards of good regulation should be enforced. Most impact can be expected if such relations are regulated by law based on a constitutional provision on the right to good governance, including the standards for public participation, impact assessment or facts, and evidence-based decision-making.

Within the processes to improve regulation, special emphasis should be put on the reduction of administrative burdens or barriers. It is suggested that the terms "administrative burden« and "administrative barrier» be distinguished. Administrative burden is any burden that brings costs and waste of time to citizens and businesses, and derives from the necessity to comply with regulation. An administrative barrier is any unnecessary administrative burden that can be removed through process optimisation without any risk for the public interest or without any change in the supervisory role of the state. The removal of administrative barriers is therefore a politically neutral process as opposed to deregulation that alters the relation between the public and private spheres. Administrative burdens are reduced through removal of administrative barriers, and by means of deregulation.

The Slovenian example of removing administrative barriers (and burdens) represents some specific features that could apply to other countries as well. It 
provides systematic prevention of new administrative barriers and a systematic approach to »clean up« the existing barriers. Such a dual approach has already given tangible and measurable results. The project for removing administrative barriers is carried out by a single ministry, and it is intended for both businesses and citizens. The focus on citizens (not merely on businesses) makes the project more attractive, and thereby increasing the reputation of public administration in society. The responsibilities for the project are distributed among various stakeholders, although the project is coordinated and conducted by the Ministry of Public Administration. The distribution of responsibilities is based on the finding that administrative barriers are not hidden only in regulation, but quite often also in its implementation. The advantage of the Slovenian model is also the fact that the removal of administrative barriers as optimisation of processes in public administration is related to the e-government projects. To prove this, the »OneStop- Shop« project won the United Nations Public Service Award - UNPSA 2009 Award in the category »Improving Service Delivery«.

\section{Notes}

${ }^{1}$ The Resolution is the basic document on regulatory policy aimed at setting a framework for and upgrading years-long efforts to improve regulation. The document was drafted in the spring of 2009, adopted by the Slovenian Government in July, and adopted as a parliamentary resolution at the end of 2009.

${ }^{2}$ Better Regulation Task Force, http://www.cabinetoffice.gov.uk/regulation/index.asp.

${ }^{3}$ For such reason, it must be bases as much as possible on quantitative data and empirical methods see Deighton-Smith in OECD, 1997, p. 213.

${ }^{4}$ Even the hypothesis that impact assessment guarantees facts-based decision-making has no empirical evidence. Such hypothesis is valid under the condition of an adequately high level of development of the regulation drafting culture and political culture. If impact assessment is considered merely as a mandatory bureaucratic procedure that needs to be carried out as one of the many steps for the adoption of a regulation, it does not play its proper role nor contributes to greater compliance of regulations with the principles of quality.

${ }^{5}$ Slovenia uses a centralised model of technical control (the »technical « existence of documents that need to form part of government materials is examined by the secretary general of the government), while content is subject to a decentralised model of control e.g. administrative barriers and cooperation with the interested public are examined by the Ministry of Public Administration, the public finance effects by the Ministry of Finance, the macroeconomic effects by the Institute for Macroeconomic Analysis and Development as a central government service, environmental impact by the Ministry of the Environment and Spatial Planning, and consistency with the law and nomotechnical correctness by the Government Office for Legislation, which is also a part of the government's centre).

${ }^{6}$ A calculation of the reduction of administrative costs in the case of the Slovenian project »One-Stop Shop« (e-VEM) for companies showed that on the assumption of full exploitation of the possibilities offered by the e-VEM information system, companies save $75 \%$ of all costs (a total of EUR 10.6 million per year) and - without any decrease of public supervision in the setting up of companies! 
${ }^{7}$ Cf. »SimpLex checklist « produced by the Board of Swedish Industry and Commerce for Better Regulation (NNR), Radaelli and De Francesco (2007, p. 97).

${ }^{8}$ A comparison between the Slovenian system of prevention of new administrative barriers and the Dutch system, which is one of the most renowned systems of this kind, shows that the main difference is that in Slovenia expert support is organised at the ministry; thus, it directly supports the work of the minister responsible for the removal of administrative barriers (minister of public administration) and is directly accountable to this minister. In the Netherlands, such role is played by the independent agency Actal (BRTF, 2005, p. 19 and 20).

${ }^{9}$ The leading positions in the service did not change over the said years, nor did any changed directives come from the top management of the ministry.

\section{References}

Bertelsmann Stiftung (2010) International Regulatory Reform Brochure 2009 (Berlin: Bertelsmann Stiftung).

Frick, F. \&. Ernst, T. (2008) International Regulatory Reform Report 2008 (Berlin: Bertelsmann Stiftung).

Hampton, P. (2005) Reducing Administrative Burdens: Effective Inspection and Enforcement (Norwich: HM Treasury).

Hardacre, A. (2008) Better Regulation - What is at Stake? Eipascope, 2, pp. 5-10.

Jacobs, S. H. (ed.), Morrall, J. F. III, Holmes, S., Argy, S., Hopkins, T. D., Viscusi, W. K., Deighton-Smith, R., Broder, I. E. (1997) Regulatory Quality and Public Sector Reform, OECD Report on Regulatory Reform (Paris: OECD).

Kirkpatrick, C., Parker, D. (eds), Jacobs, S. H., de Francesco, F., Radaelli, C. M., Ladegaard, P., Allio, L., Jacobs, C., Humperson, E., Deighton-Smith, R., Knight-John, M., Welch, D., Novion, C. C., Thomas, M. (2007) Regulatory Impact Assessment: Towards Better Regulation? (Cheltenham: Edward Elgar Publishing).

Klun, M., Slabe-Erker, R. (2009) Business views of the quality of tax, environment and employment regulation and institutions: the Slovenian case, International Review of Administrative Sciences, 75(3) pp. 529-548.

Kovač, P. (ed.), Kustec-Lipicer, S., Zatler, R., Čarni Pretnar, M., Rakar. I., Pevcin, P., Klun, M., Meuwesse, A., Prašnikar. A., Marot, N., Virant, G. (2009) Presoja učinkov regulacije - njeni elementi, cilji in pojavnost, monografija Presoja učinkov regulacije $v$ Sloveniji (Ljubljana: Faculty of Administration).

Kušej, G., Pavčnik, M.; Perenič, A. (1995) Uvod v pravoznanstvo (Ljubljana: Uradni list Republike Slovenije).

Meuwese, A. (2008) Impact Assessment in EU Lawmaking (Alphen aam den Rijn: Kluwer Laww Internationa).

OECD (1997) Regulatory Impact Analysis - Best Practices in OECD Countries (Paris: OECD).

OECD (2001) The Final Report of Mandelkern Group on Better Regulation (Paris: OECD).

OECD (2002) Regulatory Policies in OECD Countries, From Interventionism to Regulatory Governance (Paris: OECD).

OECD (2007) Cutting Red Tape - Comparing Administrative Burdens across Countries (PARIS: OECD).

OECD (2007) Regulatory Management Capacities of Member States of the European Union that joined the Union on 1st May 2004, Sustaining Regulatory Management Improvements through a Better Regulation Policy (Paris: OECD). 
OECD (2008) Building an Institutional Framework for Regulatory Impact Analysis (RIA), Guidance for Policy Makers (Paris: OECD).

Peters, B.G. \& Pierre, J. (2007) Handbook of Public Administration (New Delhi, Sage London, Thousand Oaks: SAGE)

Radaelli, C. (2007 Whither Better Regulation for the Lisbon Agenda?, Journal of European Public Policy, 14(2), pp. 190-207, doi: 10.1080/13501760601122274.

Radaelli, C. \& De Francesco, F. (2007) Regulatory Quality in Europe - Concepts, Measures and Policy Processes, (Manchester: Manchester University Press).

Schuppert, G. F. (2000) Verwaltungswissenschaft: Verwaltung, Verwaltungsrecht, Verwaltungslehre (Baden-Baden: Nomos Verlagsgesellschaft). 